\title{
Hawking With Houston
}

\section{by J. Boswell Belcher, Dilke}

Last fall the seer was out on a historic sites tour north of Saskatoon with Stuart Houston who, being a bird bander, naturally had his Sparrow Hawk trap along.

The Sparrow Hawk trap is a little wire cage built on top of a horseshoe. Inside the cage is a live mouse to lure the hawk which, if it attacks, gets its feet caught in an ingenious tangle of fine nylon nooses on top of the cage.

We spotted a Sparrow Hawk moving along by the road as we returned home. "It's simple" Stuart said, "I'll drive along till it lights on a post and as we pass it I'll slow down and you can drop the trap on the road; the horse-shoe will keep it upright." We sped along at quite a speed while I hung out the side with the door open in readiness. Finally the car slowed considerably, then started to gain speed. As I could neither see the speedometer nor watch the hawk.as I hung out the door, I was expecting to be given the word to drop the trap. However, when the speed suddenly increased: I felt I must have missed the cue so without further thought I dropped the trap. "Oh, you shouldn't have dropped it yet," Stuart protested, "the hawk hasn't landed!" That was my first blunder, and we had to go back to pick up the trap which had rolled into the weeds where it wouldn't have been any good, anyway.

We went on again and overtook the hawk conveniently perched on a post. Once again I opened the car door and hung out in readiness. I was rather uneasy hanging out in such an awkward position as we rolled along at about 20 and when I was given the word I dropped the trap from about a foot off the ground causing it to roll to the weeds at the edge. However, it was upright and not far out of sight so we drove away for a spell, but the hawk appeared uninterested and we had to pick up the trap as we were not coming back that way.

Some distance further on we came across another Sparrow Hawk. By this time I had gained confidence from my practice and previous mistakes. I coolly hung out the door holding the trap carefully level, just inches above the road, ready to drop it gently so it would sit upright on the open side of the road. Everything seemed perfect; at the signal I set the trap down carefully but as the speeding car pulled my hand away from the trap, a little noose tightened over my finger and I knew the trap would roll toward the car. The noose, of course, broke but my fears were well founded. I had rolled the trap under the rear wheel and when we backed up to collect the wreckage nothing was of salvage value except the horse-shoe! And so ended the seer's first attempt at setting Sparrow Hawk traps to help a bird bander.

Apart from this novel hawk trapping experience, the seer hasn't much to report. A few observations of the past year do however come to mind. A year ago (in June, 1960) when we were crossing the Arm Valley north of Bethune we saw an Osprey-the first I have ever seen. Then this spring, on March 21, 1961, we saw what we think was an Eastern Bluebird about two miles northwest of Findlater. When we first saw it along the roadside it didn't show much colour, but when we stopped, though we had no binoculars with us and couldn't get too close a look, it definitely showed a blue-coloured back, not bright at all like the Mountain Bluebird, and its breast appeared dull red.

Another observation I recall was made one day last summer when I was riding over the pasture to get the cows and noted a willet making fierce, excited "dive bomb" attacks at something on the ground in a shallow slough. On coming closer I could see a Marsh Hawk eating something which turned out to be a Willet, no doubt the mate of the attacking bird. It was too early in the season for this to be a young bird and anyway the feathers and carcass left no doubt it was an adult. Considering the size and activity of a mature Willet this situation was quite a surprise to me. I concluded there must have been a nest or very young birds nearby and the parent had stayed sitting too long or had been caught in an attempt to protect the young. 